\title{
Os gargalos para a provisão habitacional em municípios de pequeno porte: análise do programa Minha Casa, Minha Vida
}

\author{
Bottlenecks for housing provision in small towns: analysis of the program \\ Minha Casa, Minha Vida ("My House, My Life")
}

Karla Christina Batista de França

Universidade de Brasília (UnB), Brasília, DF, Brasil

\section{Resumo}

0 artigo tem por objetivo avaliar a adesão à política pública habitacional em municípios de pequeno porte. $\mathrm{O}$ artigo subdivide-se em duas seções. Na primeira, procura-se dimensionar as diretrizes e as necessidades habitacionais apontadas pelo Plano Nacional de Habitação (PLANHAB) em comparação ao Programa Minha Casa, Minha Vida (PMCMV) em municípios de pequeno porte; na segunda seção busca-se identificar os entraves na operacionalização do Programa Minha Casa, Minha Vida - modalidade Oferta Pública de Recursos -, destinado aos municípios com população de até 50 mil habitantes, como a descontinuidade das seleções públicas, a paralisação de recursos na modalidade oferta pública e a nova regulamentação do Programa Minha Casa, Minha Vida - Fundo de Arrendamento Residencial (FAR), que viabilizou a inserção dos municípios com população de até 50 mil habitantes para acessar fontes de recursos do FAR. As reflexões foram desenvolvidas levando em conta a revisão da literatura nacional que versa sobre a Política Nacional de Habitação e sua implementação considerando as diretrizes expressas no Plano Nacional de Habitação (PLANHAB) e parte de sua operacionalização com o lançamento do Programa Minha Casa, Minha Vida (PMCMV). Também se procedeu a uma análise das contratações do Programa Minha Casa, Minha Vida - Oferta Pública Recursos -, com base no volume de contratações das seleções de 2009 e 2012. A análise feita indica gargalos significativos para o atendimento das necessidades habitacionais em municípios de pequeno porte, bem como a dificuldade dessa classe de municípios em atender às exigências para a obtenção de recursos federais, nem sempre condizentes com sua capacidade técnica e institucional. Ao mesmo tempo, a análise aponta gargalos no gerenciamento da gestão urbana pelo poder público local.

Abstract

Palavras-chave: Política habitacional. Minha Casa, Minha Vida. Municípios pequenos. Gestão urbana.

The paper aims to assess the adhesion to the public housing policy in small towns. Thus, the article is divided into two subsections. At first, it seeks to scale the guidelines and the housing needs identified by the National Housing Plan (PLANHAB) compared to the Minha Casa, Minha Vida ("My House, My Life") (PMCMV) in small towns; and second, we seek to identify obstacles in operationalizing the Minha Casa, Minha Vida ("My House, My Life")

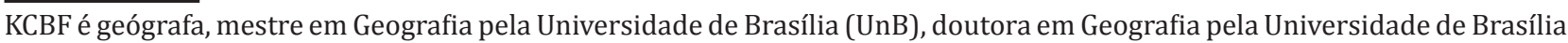
(UnB), e-mail: karla.cidades@gmail.com,karlinha@unb.br 
- modality Public Offering Resources for municipalities with up to 50 thousand inhabitants, for example, the disruption of public selections, the stoppage of resources in modality public offering and the new rules of the Minha Casa, Minha Vida ("My House, My Life") - Lease Fund Residential (FAR) which enabled the insertion of municipalities with population of up to 50 thousand inhabitants to access new sources of housing resources. The reflections were developed considering national literature review dealing with the National Housing Policy and its implementation considering expressed in the National Housing Plan (PlanHab) guidelines and part of its operation with the launch of the Minha Casa, Minha Vida ("My House, My Life") (PMCMV). Also, we proceeded to an analysis of the signings of the Minha Casa, Minha Vida ("My House, My Life") -. Public Resources Offer - based on volume of selections hires from 2009 and 2012. The analysis indicates significant bottlenecks to meet the housing needs in small towns as well as the difficulty of this class of municipalities to meet the requirements for obtaining federal resources, not always compliant to their technical and institutional capacity. At the same time, the analysis indicates resource establishment bottlenecks in the urban management by the local government.

Keywords: Housing policy. Minha Casa, Minha Vida ("My House, My Life") programm. Small municipalities. Urban management.

\section{Introdução}

Os dados do Censo de 2010 (IBGE, 2010) revelam um aumento populacional de 12,3\% no país, inferior ao da última década, de aproximadamente 15,6\%. Em termos quantitativos, o índice representa um crescimento populacional de 20.933 .524 de habitantes. Sem um planejamento e sem investimentos em políticas urbanas, os municípios brasileiros registram graves problemas, que se relacionam à qualidade de vida, ao transporte e mobilidade, desemprego e distribuição de renda, acesso a moradia digna, entre outros.

Ainda com base nos dados do Censo de 2010 (IBGE, 2010), uma parcela significativa da população vive em moradias improvisadas e/ou ocupa áreas de risco. Sabe-se que $88,6 \%$ dos aglomerados subnormais ${ }^{1}$ se concentram no município-polo

\footnotetext{
1 "O setor especial de aglomerado subnormal é um conjunto constituído de, no mínimo, 51 (cinquenta e uma) unidades habitacionais (barracos, casas...) carentes, em sua maioria, de serviços públicos essenciais, ocupando ou tendo ocupado, até período recente, terreno de propriedade alheia (pública ou particular) e estando dispostas, em geral, de forma desordenada e densa. A identificação dos Aglomerados Subnormais deve ser feita com base nos seguintes critérios: a) Ocupação ilegal da terra, ou seja, construção em terrenos de propriedade alheia (pública ou particular) no momento atual ou em período recente (obtenção do título de propriedade do terreno há dez anos ou menos); e b) Possuírem pelo menos uma das seguintes características: urbanização
}

integrante de regiões metropolitanas, por exemplo, os municípios de São Paulo, Rio de Janeiro e Belém, que, juntos, são responsáveis pela parcela de 43,7\% desses aglomerados. Esses dados revelam o quão problemática é a questão habitacional nos grandes centros urbanos e como a provisão de habitação de interesse social direcionou importantes pesquisas e programas para o enfrentamento das necessidades habitacionais em seus vários estágios nos grandes centros urbanos.

Entretanto, não menos importantes, os municípios de pequeno porte também apresentam uma série de necessidades habitacionais que nem sempre propiciaram diretrizes federais ou investimentos focalizados nessa tipologia de municípios. Historicamente, a fragilidade de estudos técnicos para identificar, dimensionar e elaborar políticas públicas com foco nas necessidades habitacionais dos pequenos municípios e a ausência de uma visão estratégica do governo federal parecem não ter demandado investimentos, capacitação,

fora dos padrões vigentes - refletido por vias de circulação estreitas e de alinhamento irregular, lotes de tamanhos e formas desiguais e construções não regularizadas por órgãos públicos; e precariedade de serviços públicos essenciais.

Os Aglomerados Subnormais podem se enquadrar, observados os critérios de padrões de urbanização e/ou de precariedade de serviços públicos essenciais, nas seguintes categorias: a) invasão; b) loteamento irregular ou clandestino; e c) áreas invadidas e loteamentos irregulares e clandestinos regularizados em período recente" (IBGE, 2011, p. 27). 
ações de fortalecimento institucional e assistência técnica significativa para a adesão às políticas e aos programas federais e sua efetividade no território em conformidade com as necessidades habitacionais.

Sabe-se que a classificação de um município como de pequeno porte apresenta diversas e divergentes conceituações que se relacionam desde o tamanho da população à posição do município na hierarquia da rede urbana brasileira. Na ciência geográfica, Sposito (2010) considera que a influência e a diversidade regional revelam o quão diversa pode ser a estrutura dos municípios de pequeno porte, a depender do seu papel da rede urbana. Não raro no Brasil, o contingente populacional entre 20-50 mil habitantes é o utilizado para classificar municípios como de pequeno porte.

Em termos de gestão pública e capacidade administrativa, há enormes discrepâncias se considerarmos dois municípios com classe populacional de até 50 mil habitantes. A assertiva de Olanda (2008, p. 184) confirma a diversidade socioeconômica que os municípios de pequeno porte apresentam:

Pequenas cidades com um contingente demográfico similar podem guardar profundas e significativas diferenças em sua constituição ao longo da história e no processo espacial que culminou com a sua atual função no sistema urbano. Dessa forma, quais são os equipamentos e serviços urbanos que a cidade dispõe? Sua importância é apenas local, ou ela extrapola os limites municipais e, mesmo sendo pequena, alcança outras cidades?

Já Veiga (2002) traz importante contribuição para dimensionar a hierarquia da rede urbana no Brasil e a inserção socioeconômica do município. Para o autor, os municípios que apresentam densidade populacional por $\mathrm{km}^{2}$ de até 80 habitantes e classe populacional de até 50 mil são considerados de pequeno porte. Para o IBGE (2011), dependendo da pesquisa, há diferentes tipologias de classe de municípios, mas, em linhas gerais, consideram-se municípios de pequeno porte aqueles situados na classe populacional de 20 mil a 50 mil habitantes, o que equivale a $89 \%$ dos municípios no Brasil, ou seja, 4.950 municípios. Conforme se pode observar na Tabela 1.

Ademais, a base tributária dos municípios de pequeno porte é limitada e em sua maioria tem como principal base tributária o repasse do Fundo de Participação dos Municípios (FPM), em virtude da baixa
Tabela 1 - Classes de tamanho da população dos municípios - 2010

\begin{tabular}{cc}
\hline Classe Populacional & Quantidade de Municípios \\
\hline Até 20.000 & 3.896 \\
$20.001-50.000$ & 1.054 \\
$50.001-100.000$ & 327 \\
$100.001-500.000$ & 250 \\
$500.001-1.000 .000$ & 22 \\
Acima de 1.000.000 & 16 \\
& 5.565 \\
\hline
\end{tabular}

Fonte: IBGE (2010).

arrecadação de outras fontes próprias. Para clarificar a importância do FPM nas finanças dos pequenos municípios, o estudo da Confederação Nacional de Municípios (CNM, 2013b, p. 5) aponta que:

O FPM é a principal transferência constitucional por parte da União aos Municípios. Na sua maioria esta é a maior fonte de recursos das pequenas e médias cidades. Ao longo dos últimos anos os dois impostos que compõem esse fundo (o IPI e o IR) vêm perdendo importância na composição da receita da União. Em 1988, o IPI e IR representavam 15\% do total da receita, apesar de o FPM ser de 20,5\%. Hoje em dia esses impostos representam $10 \%$ da receita total e o FPM é de 23,5\%. Em virtude disso, os Municípios deixaram de receber entre 1995 e 2012 o valor de R\$274.050.963.796. Com esse dinheiro poderiam ser construídas 3.915.013 casas populares no valor médio de $\mathrm{R} \$ 70.000$ cada.

Já a Pesquisa de Informações Básicas Municipais - Munic/IBGE - referente ao ano de 2011 (IBGE, 2011) traz inédito diagnóstico da capacidade técnica e institucional dos municípios no que diz respeito à gestão urbana. A pesquisa aponta os avanços e as dificuldades dos municípios de se organizarem para enfrentar os problemas urbanos e, também, para formularem estratégias para o ordenamento territorial, planejamento habitacional, afora as dificuldades de atendimento às exigências para ter acesso aos recursos federais destinados à habitação.

A pesquisa revelou que $84,6 \%$ das prefeituras possuem alguma ação ou programa no setor de 
habitação, e confirma-se a tendência de que nos municípios com população até 20 mil habitantes foram encontrados os menores índices de fomento a programas de habitação. Dito de outro modo, 81,6\% da classe de municípios com população de até 20 mil habitantes possuem algum programa de habitação, ao passo que, nos municípios com população superior a 500 mil habitantes, o porcentual eleva-se para $97,4 \%$.

É preciso considerar que os municípios de grande porte apresentam uma diversidade de problemas e carências habitacionais, além de técnica e financeiramente mostrarem uma capacidade superior de aportar recursos de diferentes fontes orçamentárias e induzir diversos projetos urbanos. Inclusive, as ações federais no campo da habitação têm como recorte prioritário os municípios de grande porte ou municípios localizados em regiões metropolitanas, diferentemente dos pequenos municípios, que apresentam grandes dificuldades administrativas e técnicas.

Conforme os dados (Quadro 1), é notável o crescimento econômico no setor habitacional em decorrência da retomada dos investimentos habitacionais. Também se observa que as ações do poder público norteadoras do atendimento às necessidades habitacionais dos municípios de pequeno porte se concentram na oferta de produto habitacional - construção de unidades habitacionais, ao passo que os produtos habitacionais, como oferta de material e lotes, ocupam, respectivamente, a 3aㅡ e 6 posições. Os dados da Munic/IBGE (IBGE, 2011) reiteram uma indução significativa do orçamento federal para produtos habitacionais que favorecem a construção de unidades habitacionais em detrimento das necessidades habitacionais prioritárias para esta classe de municípios apontadas no Plano Nacional de Habitação (PlanHab) (Brasil, 2010), que serão detalhadas na próxima seção.

Considerando este contexto, são vários os desafios dos municípios de pequeno porte para planejar e gerir seu território. Neste artigo, destacamos as assimetrias do desenho da Política Nacional de Habitação aprovada no ano de 2004 e a efetivação de suas metas por meio do Programa Minha Casa, Minha Vida.

\section{Do Plano Nacional de Habitação ao Programa Minha Casa, Minha Vida}

Na primeira década do século XXI, uma série de instrumentos e a estruturação do arcabouço institucional viabilizaram a implementação da Política Nacional de Habitação (PNH) em 2004. Marcada por um processo democrático de discussão e estruturação dos entes federados, agentes privados e sociedade civil, essa Política priorizou eixos de ações e instrumentos para sua efetivação, como a implementação dos instrumentos contidos no Estatuto da Cidade (Lei no 10.257/2001) (Brasil, 2001), a criação do Ministério das Cidades, em 2003, a aprovação das políticas setoriais - de habitação, saneamento, resíduos sólidos, mobilidade

Quadro 1 - Tipos de ações na área de habitação, segundo classes de tamanho da população dos municípios - 2011

\begin{tabular}{|c|c|c|c|c|c|c|c|}
\hline Ações & $\begin{array}{l}\text { Constrưção } \\
\text { de Unidades } \\
\text { Habitacionais }\end{array}$ & $\begin{array}{c}\text { Aquisição } \\
\text { de Unidades } \\
\text { Habitacionais }\end{array}$ & $\begin{array}{l}\text { Melhoria de } \\
\text { Unidades } \\
\text { Habitacionais }\end{array}$ & $\begin{array}{l}\text { Oferta de } \\
\text { Material de } \\
\text { Construção }\end{array}$ & $\begin{array}{l}\text { Oferta de } \\
\text { Lotes }\end{array}$ & $\begin{array}{l}\text { Regularizaccão } \\
\text { Fundiária }\end{array}$ & $\begin{array}{c}\text { Urbanização } \\
\text { de } \\
\text { Assentamentos }\end{array}$ \\
\hline Brasil & 65,6 & 23,5 & 44,3 & 36,5 & 23,1 & 31,3 & 14,2 \\
\hline Até 20 Mil/Hab & 61,1 & 19,8 & 42,8 & 36,8 & 22,2 & 23,3 & 8,5 \\
\hline $\begin{array}{l}\text { De } 20.001 \text { a } 50 \\
\text { Mil/Hab }\end{array}$ & 70,6 & 28,1 & 47,4 & 37,7 & 24,1 & 41,4 & 18,6 \\
\hline $\begin{array}{l}\text { De } 50.001 \text { a } 100 \\
\text { Mil/Hab }\end{array}$ & 83,1 & 37,7 & 47,8 & 38,9 & 28,7 & 54,3 & 31,8 \\
\hline $\begin{array}{l}\text { De } 100.001 \text { a } 500 \\
\text { Mil/Hab }\end{array}$ & 88,6 & 41,6 & 46,5 & 25,3 & 24,5 & 75,5 & 52,2 \\
\hline $\begin{array}{l}\text { Mais de } 500 \text { Mil/ } \\
\text { Hab }\end{array}$ & 97,4 & 28,9 & 55,3 & 18,4 & 28,9 & 94,7 & 89,5 \\
\hline
\end{tabular}

Fonte: Adaptado do IBGE/MUNIC-2011 (IBGE, 2011). 
urbana - e a ampliação em investimentos na provisão de infraestrutura urbana.

No campo da habitação, destaca-se a criação do Sistema Nacional de Habitação (SNH), que se subdivide em dois subsistemas. 0 primeiro é o Subsistema de Habitação de Interesse Social (SHIS), composto de fundos públicos para atender à demanda da população de baixa renda. 0 outro é o Subsistema de Habitação de Mercado (SHM), constituído de recursos do Sistema Brasileiro de Poupança e Empréstimo (SBPE) e do Sistema Financeiro Imobiliário (SFI), com ênfase na ampliação do fomento à habitação para a iniciativa privada. Nesse âmbito de atuação, o objetivo é atender e reduzir a demanda da população de classe média aos financiamentos públicos.

O Sistema Nacional de Habitação de Interesse Social (SNHIS) foi regulamentado pela Lei no 11.124 / 2005 (Brasil, 2005). Os governos locais e estaduais que voluntariamente aderiram ao SNHIS concordaram em cumprir os requisitos obrigatórios que regulam o sistema, isto é, a instituição de Fundos, Conselhos e Planos Locais de Habitação como condição para governos locais e estaduais conseguirem recursos do Fundo Nacional de Habitação de Interesse Social (FNHIS).

O objetivo do SNHIS é viabilizar a cooperação entre a União, estados, Distrito Federal e municípios para o enfrentamento do déficit habitacional brasileiro quantitativo e qualitativo -, por meio da articulação de recursos (dos Fundos), planos, programas e ações. Busca-se a ampliação da destinação de recursos não onerosos e onerosos ${ }^{2}$ por parte da União, estados, Distrito Federal e municípios, canalizando-os para o Fundo Nacional de Habitação de Interesse Social (FNHIS) e respectivos fundos habitacionais municipais e estaduais (Brasil, 2005).

\footnotetext{
${ }^{2}$ Recursos onerosos são aqueles que exigem retorno (pagamento) e estão vinculados a operações de crédito ou financiamentos. São exemplos de recursos onerosos os programas que operam recursos do FGTS. Podem ser mutuários neste tipo operação um estado, um município, uma empresa pública, uma empresa particular (uma concessionária privada de saneamento, por exemplo), uma entidade/associação e um indivíduo específico (como nas operações coletivas do FGTS com subsídio). Recursos não onerosos são aqueles que não exigem retorno, apenas contrapartida, e estão vinculados a operações de repasse. Geralmente, são destinados a estados, municípios ou entidades/organizações não governamentais. 0 principal exemplo são os programas vinculados aos recursos do Orçamento Geral da União (OGU).
}

Na prática, a transferência via fundos não ocorreu. E a articulação do SNHIS não tem resultado em medidas concretas e eficazes diante dos vultosos investimentos habitacionais direcionados para programas que operam de forma distinta das diretrizes estabelecidas pelo SNHIS, como o Programa Minha Casa, Minha Vida (PMCMV).

0 esforço em articular e planejar o setor habitacional considerando a descentralização e o papel dos municípios revelou-se na estrutura do Sistema Nacional de Habitação de Interesse Social (SNHIS) e nas diretrizes estabelecidas no Plano Nacional de Habitação (PlanHab). Para tanto, uma das ações centrais do PlanHab visa ao fortalecimento institucional da gestão urbana municipal, para o desenvolvimento de um arcabouço institucional em articulação com os entes federados, assim como de um planejamento e adoção de instrumentos capazes de atender às necessidades de demanda habitacional, com produtos habitacionais adequados (Brasil, 2005, 2010).

Há um reconhecimento no desenho do plano nacional das distintas capacidades institucionais e necessidades habitacionais dos municípios. Ou seja, no plano não se elaboraram estratégias padronizadas, tendo em vista as diferentes realidades municipais. Assim, o PlanHab desenvolveu uma metodologia que buscou classificar os municípios brasileiros em tipologias para melhor dimensionar as necessidades habitacionais e os produtos habitacionais adequados. A metodologia se revelou inovadora nas diretrizes da Política Nacional de Habitação, se considerarmos que anteriormente o desenho das políticas habitacionais e dos programas não era pautado em estudos técnicos aprofundados para dimensionar as distintas necessidades habitacionais dos municípios de pequeno porte e os produtos adequados (Brasil, 2010).

0 dimensionamento das características urbanas das diferentes categorias de municípios (Tabela 2) revelou a importância de indicar a composição do déficit habitacional, o déficit de urbanização e as necessidades habitacionais presentes e futuras, bem como os tipos de produtos habitacionais adequados que devem orientar a formulação das políticas públicas (Brasil, 2010).

Considerando as tipologias expressas no PlanHab, os municípios com porte populacional de até $50 \mathrm{mil}$ estão inclusos em duas tipologias: a primeira agrupa municípios nas tipologias F, G e H com porte populacional de até 100 mil. Englobam as tipologias F, 
Tabela 2 - Síntese da tipologia de municípios adotada no PlanHab

\begin{tabular}{llc}
\hline \multicolumn{1}{c}{ Faixa Populacional } & \multicolumn{1}{c}{ Tipologia } & Número de Municípios \\
\hline Mais de 100 mil/hab e Regiões & A) RMs do Rio de Janeiro e de São Paulo & 59 \\
Metropolitanas & B) Principais aglomeraç̃óes e capitais ricas & 186 \\
& C) Aglomerados e capitais prósperas do N e do NE & 63 \\
& D) Aglomerados e centros regionais do Centro-Sul & 215 \\
De 20 mil a 100 mil habitantes & E) Aglomerados e centros regionais do N e do NE & 58 \\
& F) Centros urbanos em espaços rurais prósperos & 250 \\
Menos de 20 mil habitantes & g) Centros urbanos em espaços rurais de média renda no Centro-Sul & 274 \\
& H) Centros urbanos em espaços rurais com elevada desigualdade e pobreza & 587 \\
Total & I) Pequenas cidades em espaç,os rurais prósperos & 1.002 \\
\hline
\end{tabular}

Fonte: Krause et al. (2013).

G e H 1.112 municípios, dos quais 876 possuem porte populacional de 50 mil. Estes municípios estão situados predominantemente nas regiões Norte e Nordeste e com níveis de precariedade e pobreza acentuados. Já na segunda tipologia, estão agrupados os tipos I, J e K, com população inferior a 20 mil habitantes. Foram agrupados nessa tipologia 3.819 municípios, representando 35,84\% do déficit habitacional total. Nessas tipologias estão concentrados 70\% do déficit habitacional rural e agrupados os municípios mais pobres e que possuem taxas elevadas de precariedade dos domicílios rurais e urbanos (Brasil, 2010).

As tipologias I, J e K representam as cidades localizadas em municípios com menos de 20 mil habitantes, com fortes características rurais e seus diversos contextos urbanos, socioambientais, socioeconômicos e políticos, entre outros. São municípios com taxa de urbanização menor e cerca de metade da População Economicamente Ativa (PEA) trabalhando no setor primário. Em linhas gerais, esses municípios apresentam o preço da terra reduzido, e grande parte do problema habitacional se relaciona com a ausência de saneamento básico, infraestrutura urbana, e as necessidades habitacionais em sua maioria apresentam conexões com as questões rurais (Brasil, 2008).

As tipologias municipais adotadas no PlanHab revelaram as distintas necessidades habitacionais que deveriam orientar a focalização dos produtos habitacionais para o enfrentamento dos problemas urbanos. No Quadro 2 apresenta-se a distribuição dos produtos habitacionais recomendados para as diversas tipologias de municípios.

Considerando as necessidades habitacionais para os municípios da classe populacional de até $50 \mathrm{mil}$, os estudos do PlanHab recomendaram a elaboração de políticas públicas e programas habitacionais que priorizassem como produtos habitacionais: lote urbanizado com cesta de material e assistência técnica; unidade térrea de $20 \mathrm{~m}^{2}$ (autogestão com assessoria); unidade com dois pavimentos de $56 \mathrm{~m}^{2}$ (autogestão com assessoria); casa de $40 \mathrm{~m}^{2}$ (empreiteira); casa de $56 \mathrm{~m}^{2}$ (empreiteira). Apesar da recomendação de outros produtos habitacionais nos tipos F, G e $\mathrm{H}$, sublinha-se que nos tipos F, G e H estão inclusos municípios com população de até 100 mil habitantes. Os demais produtos recomendados apresentam sintonia com a realidade dos municípios que possuem porte populacional superior a 50 mil habitantes, inclusos nas tipologias F, G e H.

Portanto, nas diretrizes apontadas pelo PlanHab identifica-se a diversidade de necessidades habitacionais e os distintos produtos habitacionais a serem priorizados na elaboração de políticas e programas habitacionais para os municípios de pequeno porte. Embora o PlanHab aponte para esta classe de municípios com população inferior a 50 mil a necessidade de programas focalizados 
Quadro 2 - Distribuição prioritária de produtos para atendimento em escala, por tipologia de município I - PlanHab

\begin{tabular}{|c|c|c|c|c|c|c|c|c|c|c|c|}
\hline \multirow{3}{*}{ Tipologia/Produto } & \multicolumn{11}{|c|}{ Tipologia de Municípios } \\
\hline & \multicolumn{5}{|c|}{$\begin{array}{l}\text { Regiōes metropolitanas, capitais } \\
\text { e municipios com + de } 100 \text { mil habitantes }\end{array}$} & \multicolumn{3}{|c|}{ De 20 a 100 mil habitantes } & \multicolumn{3}{|c|}{$\begin{array}{l}\text { Menos de } \mathbf{2 0} \text { mil } \\
\text { habitantes }\end{array}$} \\
\hline & Tipo A & Tipo B & Tipo C & Tipo D & Tipo E & Tipo F & Tipo G & Tipo H & Tipo I & Tipo J & Tiрo K \\
\hline \multicolumn{12}{|l|}{ Lote urbanizado } \\
\hline \multicolumn{12}{|l|}{$\begin{array}{l}\text { Material de construução para reforma } \\
\text { e ampliação }\left(16 \mathrm{~m}^{2}\right)\end{array}$} \\
\hline \multicolumn{12}{|l|}{$\begin{array}{l}\text { Material de construcũão para unidade } \\
\text { térrea }\left(32 \mathrm{~m}^{2}\right)\end{array}$} \\
\hline \multicolumn{12}{|l|}{$\begin{array}{l}\text { Unidade térrea (autogestão com } \\
\text { assessoria) }\left(32 \mathrm{~m}^{2}\right)\end{array}$} \\
\hline \multicolumn{12}{|l|}{$\begin{array}{l}\text { Unidade de } 2 \text { pavimentos (autoges- } \\
\text { tão com assessoria) (56 m²) }\end{array}$} \\
\hline \multicolumn{12}{|l|}{ Apartamento (autogestão) $\left(51 \mathrm{~m}^{2}\right)$} \\
\hline \multicolumn{12}{|l|}{ Casa (empreiteira) $\left(40 \mathrm{~m}^{2}\right)$} \\
\hline \multicolumn{12}{|l|}{ Casa (empreiteira) $\left(56 \mathrm{~m}^{2}\right)$} \\
\hline \multicolumn{12}{|l|}{ Apartamento (empreiteira) (37 m²) } \\
\hline \multicolumn{12}{|l|}{ Apartamento (empreiteira) (51 m²) } \\
\hline \multicolumn{12}{|l|}{$\begin{array}{l}\text { Unidade em área central/consolida- } \\
\text { da (empreiteira) }\left(51 \mathrm{~m}^{2}\right)\end{array}$} \\
\hline \multicolumn{12}{|l|}{ Unidades de padrão médio FGTS } \\
\hline Unidades de mercado SBPE & & & & & & & & & & & \\
\hline
\end{tabular}

Fonte: Consórcio Via Pública/FUPAM - LABHAB (Brasil, 2008). Adaptado pela autora.

na construção de novas unidades habitacionais, é priorizado para os pequenos municípios a criação de programas que facilite o acesso ao lote urbanizado, subsídios para aquisição de material de construção e melhoramento das moradias. Portanto, infere-se que o produto construção de unidade habitacional não se caracteriza como prioridade para o enfrentamento das necessidades habitacionais (Brasil, 2010).

Considerando as recomendações do PlanHab e a implementação das suas diretrizes com a criação do Programa Minha Casa, Minha Vida lançado no ano de 2009, procura-se verificar a adesão às tipologias de produtos recomendados e a focalização dos produtos habitacionais efetivados com base na operacionalização do Programa Minha Casa, Minha Vida - modalidade Oferta Pública de Recursos, conhecida popularmente como Sub-50 mil.

\section{A provisão habitacional nos municípios de pequeno porte: balanço do Programa Minha Casa, Minha Vida - Oferta Pública de Recursos}

Apesar do amplo e democrático processo de elaboração do Plano Nacional de Habitação e as respostas específicas para o enfrentamento das necessidades habitacionais em sintonia com as diversas tipologias dos municípios, o que se efetiva no território brasileiro são as diretrizes e metas do Programa Minha Casa, Minha Vida.

O Programa Minha Casa, Minha Vida, lançado em abril de 2009, foi regulamentado pela Lei Federal no 11.977/2009 (Brasil, 2009). Sua finalidade é ampliar o acesso à aquisição de unidades habitacionais, com subsídios voltados para a melhoria de imóveis urbanos e rurais. A estratégia é reduzir o déficit habitacional e aquecer a economia brasileira com a criação de 
empregos e aumento dos investimentos no segmento da construção civil.

Em resposta à crise econômica, o governo federal lançou o "pacote" habitacional Minha Casa, Minha Vida, contando com a participação de setores econômicos específicos, sobretudo aqueles da construção civil, mediante negociação realizada com a Casa Civil e o Ministério da Fazenda. 0 objetivo era enfrentar a crise econômica internacional de 2008, que afetou setores estratégicos da economia brasileira. 0 cenário de crise facilitou a defesa do alto escalão do governo em elaborar o programa sem interlocução com os demais agentes governamentais e sociedade, no momento em que os estudos do PlanHab, encomendados pelo próprio governo, estavam em fase de finalização e apontando uma pluralidade de estratégias a serem implementadas com a regulamentação do Sistema Nacional de Habitação de Interesse Social (Fix, 2011).

No entanto, o governo federal priorizou a alocação de investimentos no Programa Minha Casa, Minha Vida de forma desarticulada dos recentes marcos institucionais que procuravam centralizar os recursos habitacionais no Fundo Nacional de Habitação de Interesse Social (FNHIS), para viabilizar de forma articulada as distintas necessidades habitacionais. A tomada de decisão de alocar vultosos recursos fora do marco do SNHIS enfraqueceu o papel dos entes municipais e estaduais e fragilizou o recente sistema de habitação. A assertiva de Bonduki (2013) aponta as escolhas e priorizações do governo federal em consonância com os interesses privados.

0 próprio papel do FNHIS na política habitacional foi se reduzindo à medida que o governo federal avançou na alocação de recursos para o setor de habitação. Inicialmente, quando o fundo foi aprovado em 2005, o governo Lula se comprometeu a alocar no fundo, anualmente, um bilhão de reais, valor considerável para a época. Entretanto, com a criação do Programa de Aceleração do Crescimento (PAC), especialmente o eixo Urbanização de Assentamentos Precários em 2007 e sobretudo o Programa Minha Casa, Minha Vida em 2009, esse valor mostrou-se pouco relevante, uma vez que o governo federal decidiu alocar os recursos não onerosos para os novos programas sem incorporá-los ao FNHIS. Assim, no momento em que o governo federal elevou significativamente o investimento em Habitação, sua destinação ficou independente das exigências estabelecidas para que os municípios aderissem ao SNHIS (Bonduki, 2013, p. 37).

Na primeira etapa do programa, os investimentos públicos no setor habitacional somaram $\mathrm{R} \$ 34$ bilhões, isto é, considerando o ciclo do Plano Plurianual (PPA) 2008-2011. Já na segunda fase, o programa Minha Casa, Minha Vida foi incorporado ao Programa de Aceleração do Crescimento (PAC), formando PAC-MCMV, sendo destinados R\$278 bilhões para produção e financiamento habitacional, urbanização de assentamentos precários no período 2011-2014. São três as grandes linhas de ação do programa Minha Casa, Minha Vida: ações de urbanização em assentamentos precários; financiamento habitacional pelo Sistema Brasileiro de Poupança e Empréstimo (SBPE) e provisão de unidades habitacionais. 0 programa opera a partir das seguintes modalidades: Programa Nacional de Habitação Urbana (PNHU); Programa Nacional de Habitação Rural (PNHR); Programa Minha Casa, Minha Vida - Entidades (PMCMV-E); e Programa Minha Casa, Minha Vida - Oferta Pública de Recursos (PMCMV-OPR) (Brasil, 2010).

Já em relação à provisão de unidades habitacionais, o programa está distribuído em três faixas de renda. Para famílias com renda de até $\mathrm{R} \$ 1.600,00$, incluídas na Faixa I, a meta era construir 400 mil unidades, através do Fundo de Arrendamento Residencial (FAR), do PMCMV - Entidades, do Programa de Habitação Rural (PNHR) e do Programa Oferta Pública de Recursos. Já para a Faixa II, famílias com renda bruta de até $\mathrm{R} \$ 3.100,00$, a meta era construir $600 \mathrm{mil}$ unidades, por intermédio do Programa Nacional de Habitação Urbana (PNHU) e do Programa Nacional de Habitação Rural (PNHR). Para a Faixa de renda III, o programa visa atender famílias com renda bruta de até $\mathrm{R} \$ 5.000,00$, com a meta de construir $200 \mathrm{mil}$ unidades habitacionais (Brasil, 2010).

Considerando o volume de contratações apresentado nas Tabelas 3 e 4, o Programa Minha Casa, Minha Vida já contratou mais de 3 milhões de unidades habitacionais. Observa-se uma superação da meta prevista, ou que a meta está próxima de ser atingida. Considerando apenas a segunda fase do programa, já foram investidos aproximadamente $\mathrm{R} \$ 156$ bilhões.

Vale lembrar que na estrutura do Programa Minha Casa, Minha Vida não havia previsão de uma linha de financiamento específico aos pequenos municípios enquadrados na tipologia F, G, H, I, J e K do PlanHab. Somente após a mobilização de representantes 
Tabela 3 - Contratação por tipo de Modalidade: PMCMV - $1^{0}$ fase

\begin{tabular}{|c|c|c|c|c|}
\hline \multirow{2}{*}{ Renda } & \multirow{2}{*}{ Modalidade* } & \multirow{2}{*}{ Contratadas } & \multicolumn{2}{|c|}{ Estágio de Execução } \\
\hline & & & Concluidas & Entregues \\
\hline \multirow[t]{4}{*}{ Faixa 1} & Empresas (FAR) & 404.128 & 351.531 & 312.786 \\
\hline & Entidades (FDS) & 8.024 & 4.728 & 2.305 \\
\hline & Rural & 6.817 & 6.403 & 6.371 \\
\hline & FGTS até $R \$ 1.600^{\star *}$ & 88.121 & 104.424 & 106.541 \\
\hline Faixa 2 & FGTS de RS 1.600 até $R \$ 3.275$ & 287.643 & 259.013 & 225.785 \\
\hline \multirow[t]{2}{*}{ Faixa 3} & FGTS de R\$ 3.275 até $R \$ 5.000$ & 146.623 & 114.474 & 69.145 \\
\hline & Total & 941.356 & 840.573 & 722.933 \\
\hline
\end{tabular}

Fonte: Balanço relativo até 0 dia 31/3/2014 (Brasil, 2014a). ${ }^{\star} 0$ volume de contratações da Modalidade Oferta Pública de Recursos não está incluso. ${ }^{\star \star C}$ Contratação Pessoa Física.

Tabela 4 - Contratação por tipo de Modalidade: PMCMV - $2^{a}$ fase

\begin{tabular}{|c|c|c|c|c|}
\hline \multirow{2}{*}{ Renda } & \multirow{2}{*}{ Modalidade* } & \multirow{2}{*}{ Contratadas } & \multicolumn{2}{|c|}{ Estágio de Execução } \\
\hline & & & Concluídas & Entregues \\
\hline \multirow[t]{5}{*}{ Faixa 1} & Empresas (FAR) & 789.116 & 123.655 & 61.207 \\
\hline & Urbanização (FAR) & 36.843 & 5.348 & 2.206 \\
\hline & Entidades (FDS) & 27.492 & 5.081 & 907 \\
\hline & Rural & 118.435 & 35.681 & 35.637 \\
\hline & FGTS até RS 1.600 & $144.436^{\star \star}$ & 139.515 & 139.207 \\
\hline Faixa 2 & FGTS de $R \$ 1.600$ até $R \$ 3.100$ & 799.324 & 555.662 & 483.453 \\
\hline \multirow[t]{2}{*}{ Faixa 3} & FGTS de $R \$ 3.100$ até $R \$ 5.000$ & 265.026 & 94.097 & 50.401 \\
\hline & Total & 2.036 .236 & 959.039 & 773.018 \\
\hline
\end{tabular}

Fonte: Balanço relativo até o dia 31/3/2014 (Brasil, 2014a). *0 volume de contrataccōoses da Modalidade Oferta Pública de Recursos não está incluso. **Contratação Pessoa Física.

políticos, prefeitos, gestores, representantes das Companhias de Habitação Popular (Cohabs), das entidades municipalistas, a Câmara dos Deputados acrescentou o inciso III do artigo 2 na Lei Federal no 11.977/2009 (Brasil, 2009), ou seja, assegurou uma modalidade do Programa Minha Casa, Minha Vida para atender os municípios de pequeno porte, isto é, aqueles com população de até 50 mil habitantes, conforme se observa no texto legislativo:

III - realizará oferta pública de recursos destinados à subvenção econômica ao beneficiário pessoa física de operações em Municípios com população de até 50.000 (cinquenta mil) habitantes (Incluído pela Lei $\mathrm{n}^{0}$ 11.977, de 2009) (Brasil, 2009).

Também consta na Lei no 11.977/2009 (Brasil, 2009) a meta de produção habitacional do Programa Minha Casa, Minha Vida - Operação de Recursos Públicos. A meta do programa até o final do PMCMV-2, isto é, dezembro de 2014, é de contratar 220 mil unidades habitacionais. A regulamentação do Programa Minha Casa, Minha Vida - Oferta Pública de Recursos configurou-se em uma importante ação de alocação de investimentos, viabilizando o atendimento de parte das necessidades habitacionais, além de gerar renda, emprego e aquecer a economia regional nos municípios de pequeno porte. 
Segundo a Secretaria Nacional de Habitação (SNH), o papel do município no programa é de protagonista, indutor, articulador e estruturador para a implementação do programa, por exemplo, na indicação dos beneficiários, na doação do terreno com boa infraestrutura, na seleção da empresa construtora e execução do trabalho técnico-social. De acordo com o portfólio do programa, existem uma flexibilização e menos burocracia na operacionalização desta modalidade para o atendimento das necessidades habitacionais, em decorrência da possibilidade de os municípios contratarem pequenas construtoras e instituições financeiras regionais, o que traz benefícios para a economia local, como a contratação de mão de obra local ou compras no comércio da região (Brasil, 2014a).

Com base nos relatórios de execução do Programa Minha Casa, Minha Vida ${ }^{3}$ é possível analisarmos preliminarmente o fluxo de investimentos, metas e execução do programa na modalidade Oferta Pública de Recursos (Brasil, 2014b).

A primeira seleção (Tabela 5) do programa ocorreu no ano de 2009. Dos 3.763 municípios que apresentaram propostas, 2.079 foram selecionados.

Na seleção de 2009, é possível notar de forma desagregada as unidades habitacionais contratadas pela instituição financeira Banco Morada S.A. Este fato se deve à decretação de intervenção do Banco Morada S.A. pelo Banco Central do Brasil (Bacen) no mês de abril de 2011. Os municípios que haviam contratado a instituição financeira Banco Morada S.A. tiveram suas obras paralisadas no estágio em que se encontravam. Segundo dados oficiais do Ministério das Cidades (Brasil, 2014b), este era o caso de 135 municípios, com 5.699 unidades habitacionais em tal situação.

Entretanto, ao verificarmos a legislação acerca da adoção de procedimentos para os municípios interessados na retomada e conclusão das obras (Ministério das Cidades, Portarias 45/2014 e 229/2014) ${ }^{4}$ (Brasil, 2014c, d), notamos que o número de municípios cuja Manifestação de Interesse foi aprovada era de 1.097 (um mil e noventa e sete) e

\footnotetext{
${ }^{3}$ A base de dados refere-se ao balanço preliminar da Modalidade Oferta Pública de Recursos até o mês de fevereiro do ano de 2014.

${ }^{4}$ A Portaria 45/2014 dispõe sobre os procedimentos para a retomada e conclusão das obras. Já a Portaria 229/2014 dispõe sobre as propostas aprovadas para a retomada das obras.
}

de unidades habitacionais a serem concluídas ou entregues, de 21.171. Ou seja, trata-se de quantitativo bem superior aos primeiros dados oficiais divulgados. A demora na retomada das obras paralisadas por aproximadamente três anos revela, assim, a baixa celeridade do governo federal em buscar respostas adequadas e agilidade na conclusão e entrega de obras paralisadas.

No ano de 2012, foi realizada a segunda seleção do programa. De um total de 4.042 municípios que apresentaram propostas, 2.582 foram selecionados. Esse dado mostra um crescimento do número de municípios interessados em pleitear recursos e também uma pequena elevação do número de municípios selecionados. A Tabela 6 apresenta o volume de contratação da segunda seleção do programa.

Considerando as duas ofertas públicas, 4.661 municípios foram selecionados para executar obras habitacionais e 166.866 mil famílias serão atendidas. Vale lembrar que as seleções de 2009 e 2012 estabeleceram a quantidade máxima de 30 unidades habitacionais passíveis de serem contratadas pelas prefeituras em municípios com população de até 20 mil habitantes e

Tabela 5 - Balanço Programa Minha Casa, Minha Vida - Sub-50: Seleção 2009

\begin{tabular}{crc}
\hline Unidades Contratadas & \multicolumn{2}{c}{$\mathbf{6 9 . 4 4 2}$} \\
\hline Obras Concluídas e Entregues & $\mathbf{4 0 . 4 1 0}$ & $\mathbf{5 8 , 1 7 \%}$ \\
\hline Obras Concluídas & 9.620 & $13,85 \%$ \\
Obras em Andamento & 11.551 & $16,66 \%$ \\
Contratação Banco Morada & 5.699 & $8,21 \%$ \\
Obras Recursos Devolvidos -Solicitada & 2.162 & $3,11 \%$ \\
Devolução & & \\
\hline
\end{tabular}

Fonte: Balanço até fev. 2014 (Brasil, 2014a).

Tabela 6 - Balanço do Programa Minha Casa, Minha Vida: OPR - 2012

\begin{tabular}{ccc}
\hline Unidades Contratadas & \multicolumn{2}{c}{$\mathbf{9 7 . 4 4 4}$} \\
\hline Entregues & $\mathbf{2 . 6 5 0}$ & $\mathbf{2 , 7 2 \%}$ \\
\hline Recursos Devolvidos - Operações Canceladas & 322 & $0,33 \%$ \\
Não Iniciadas & 7.779 & $7,98 \%$ \\
Em Andamento & 86.693 & $88,97 \%$ \\
\hline
\end{tabular}

Fonte: Balanço até fev. 2014 (Brasil, 2014a). 
60 unidades em municípios com população de 20 mil a 50 mil habitantes em cada proposta apresentada. Para a modalidade Oferta Pública de Recursos considerando apenas a segunda fase do programa, foram investidos aproximadamente $\mathrm{R} \$ 2,52$ bilhões.

O enquadramento para a seleção e aprovação da proposta leva em consideração os critérios estabelecidos no art. $4^{\circ}$ do Decreto ${ }^{\circ}$ 7.499, de 2011, quais sejam: a) a doação pelos estados, pelo Distrito Federal e pelos municípios de terrenos localizados em área urbana consolidada para construção de empreendimentos vinculados ao programa; b) a implementação pelos estados, pelo Distrito Federal e pelos municípios de medidas de desoneração tributária para as construções destinadas à habitação de interesse social; e c) a implementação pelos municípios dos instrumentos urbanísticos que visam ao controle da retenção das áreas urbanas em ociosidade. Além desses critérios, também são considerados a infraestrutura a ser disponibilizada pelo Proponente, a condição do terreno, o atendimento e adequação ao déficit habitacional e o índice dos domicílios em situação de extrema pobreza (Brasil, 2011).

Atualmente, há cerca de 90 mil unidades habitacionais em construção, considerando as contratações das ofertas de 2009 e 2012, respectivamente 69 mil e 97 mil. No ano de 2013, foi aberta a terceira seleção do PMCMV - Oferta Pública de Recursos. Nesta seleção houve modificação em relação à faixa populacional e unidades habitacionais passíveis de serem contratadas em cada proposta pelo Proponente (município ou estado). Para os municípios com população de até 15 mil habitantes, caberia contratar até 30 unidades habitacionais; e para os municípios com população entre 15.001 e 50.000 , caberia contratar até 60 unidades habitacionais.

Ao total, 4.486 municípios encaminharam propostas na seleção para a oferta de 2013, entretanto, esta seleção foi cancelada pela Secretaria Nacional de Habitação, em função dos problemas de operacionalização do programa, como obras paralisadas em decorrência de atrasos no repasse de recursos federais, atrasos nas medições, execução de projetos diferentes dos aprovados, dificuldade no cumprimento das exigências pela gestão local.

A impossibilidade de contratação dos empreendimentos pelos municípios com população de até 50 mil habitantes por meio da modalidade Oferta Pública e a solução apresentada pelo governo federal de incorporar esta classe de município em outra modalidade do Programa Minha Casa, Minha Vida trazem dificuldades para os municípios terem acesso a recursos diante da nova configuração do programa. Com a regulamentação da Portaria Portaria no 363/2013 (Brasil, 2013), houve a possibilidade de contratação dos pequenos municípios através do Fundo de Arrendamento Residencial (FAR). Vale enfatizar que foram estabelecidos critérios distintos da modalidade Oferta Pública. Está prevista, segundo estimativa da Secretaria Nacional de Habitação, a contratação de 135 mil unidades habitacionais para esta classe de municípios via modalidade PMCMV-FAR.

Considerando o cancelamento da seleção de 2013 da modalidade Oferta Pública, restou aos municípios com população inferior a 50 mil habitantes a modalidade do Programa Minha Casa, Minha Vida - FAR. Nesta modalidade, o fluxo é contínuo, ou seja, não existe o elemento "seleção", recorrente na modalidade Oferta Pública de Recursos.

A modalidade FAR apresenta critérios distintos dos aplicados à modalidade Oferta Pública de Recursos. Por exemplo, há uma concentração de grandes construtoras que operam no FAR; já na modalidade Oferta pública predominam as pequenas construtoras, o que dá celeridade ao processo de contratação e construção, especialmente em função da pluralidade de agentes. No desenho do FAR, os pequenos municípios enfrentam graves dificuldades quanto à contratação das grandes empresas, por conta do reduzido interesse das construtoras em incorporar, em sua carteira de produtos, a operacionalização de pequenos projetos que não proporcionam alta lucratividade (Brasil, 2013).

0 que nos faz levantar a seguinte hipótese: que a provisão de unidades habitacionais em pequenos municípios sem potencial de um mercado imobiliário desenvolvido e a baixa escala de produção habitacional não conseguem atrair grandes construtoras com capacidade de atender aos critérios de seleção e aprovação dos projetos pela Caixa Econômica Federal.

Além disso, as especificações técnicas dos projetos encarecem a execução da obra, sendo insuficiente o valor da unidade ${ }^{5}$ habitacional estipulado nesta modalidade, o que é outro fator que dificulta a inserção das grandes construtoras. Nesse sentido, até junho do ano de 2014, nenhum município com população inferior a 50 mil habitantes havia contratado unidades

\footnotetext{
${ }^{5} \mathrm{O}$ valor da unidade equivale ao limite de $\mathrm{R} \$ 35$ mil reais.
} 
habitacionais pelo PMCMV-FAR. Infere-se que a meta de contratação de 135 mil unidades habitacionais pelos municípios com população inferior a $50 \mathrm{mil}$ habitantes não será atingida na modalidade FAR.

Na prática, o papel do poder público local parece estar condicionado aos interesses dos agentes imobiliários e das construtoras na execução dos projetos habitacionais. Ademais, o custo de construção, como acesso à mão de obra e matéria-prima nos municípios de pequeno porte, encarece o projeto cuja unidade habitacional tem um financiamento menor, se comparado ao financiamento das unidades habitacionais das outras modalidades do programa destinado aos municípios com população superior a 50 mil habitantes. As prefeituras dos municípios de pequeno porte, sobretudo aqueles municípios situados em áreas rurais mais pobres, apresentam um mercado imobiliário estagnado e forte carência em capacidade administrativa para planejar e gerir a oferta de terrenos com infraestrutura integrada à dinâmica do município (CNM, 2013a; IPEA, 2012; Akaishi, 2013).

O deslocamento de investimentos e a priorização para $o$ atendimento das necessidades habitacionais a partir da padronização de projetos no programa Minha Casa, Minha Vida são determinados pelos interesses do mercado imobiliário, instituições financeiras e das construtoras que visam otimizar os custos determinando a localização e aprovação dos terrenos e a tipologia dos empreendimentos.

A título de exemplificação, as Figuras 1, 2 e 3 revelam a padronização da tipologia habitacional "casa" nos pequenos municípios. Em geral, observa-se uma produção habitacional desprovida de infraestrutura urbana. Ao mesmo tempo, observa-se o tamanho reduzido de unidades e uma produção desintegrada de espaços de lazer e serviços urbanos.

As Figuras 1, 2 e 3 que ilustram este artigo referem-se à seleção de 2009. Notam-se diferenciados estágios de andamento das obras e também diferentes contextos de planejamento urbano. Em comum, há fragilidade de provisão de infraestrutura urbana nas áreas próximas dos empreendimentos. Em relação ao empreendimento da Figura 1, observa-se que a destinação da área do terreno não considerou as zonas de interesse social previstas no plano diretor. Na Figura 2, a produção habitacional foi realizada no limite entre área rural e urbana e distante das áreas de serviços urbanos. Vale ressaltar, que o contexto urbano do município da Figura 2 está alinhavado com fortes referências rurais e porte populacional inferior a 3 mil habitantes.

Já na Figura 3, observam-se ações de desenvolvimento urbano estratégico em parceria com centros de ensino superior. Embora o município apresente população inferior a 20 mil habitantes e não possua obrigatoriedade de elaborar plano diretor, nota-se certo protagonismo do poder local e fortalecimento de novas institucionalidades para a promoção de habitação social e desenvolvimento urbano. No entanto,

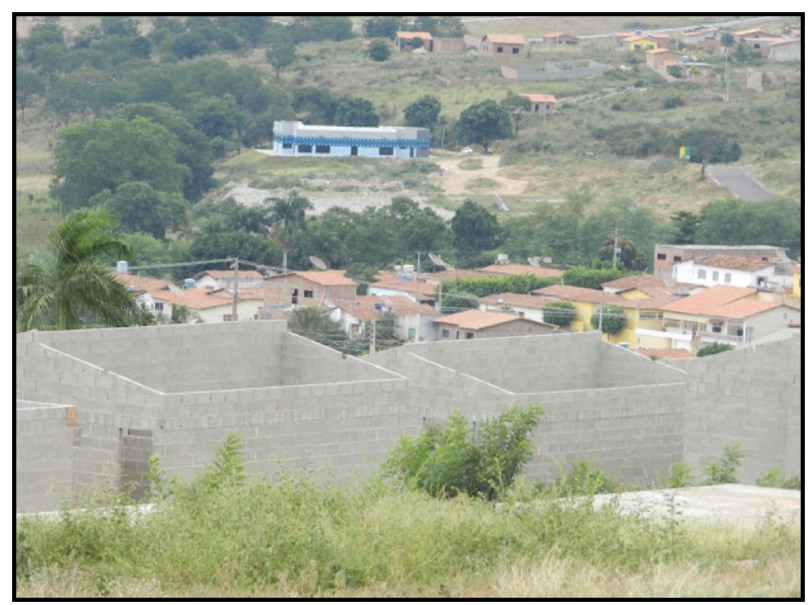

Figura 1 - Unidades Habitacionais - Macaúbas - BA (em andamento) Fonte: $A B C$ (2014).

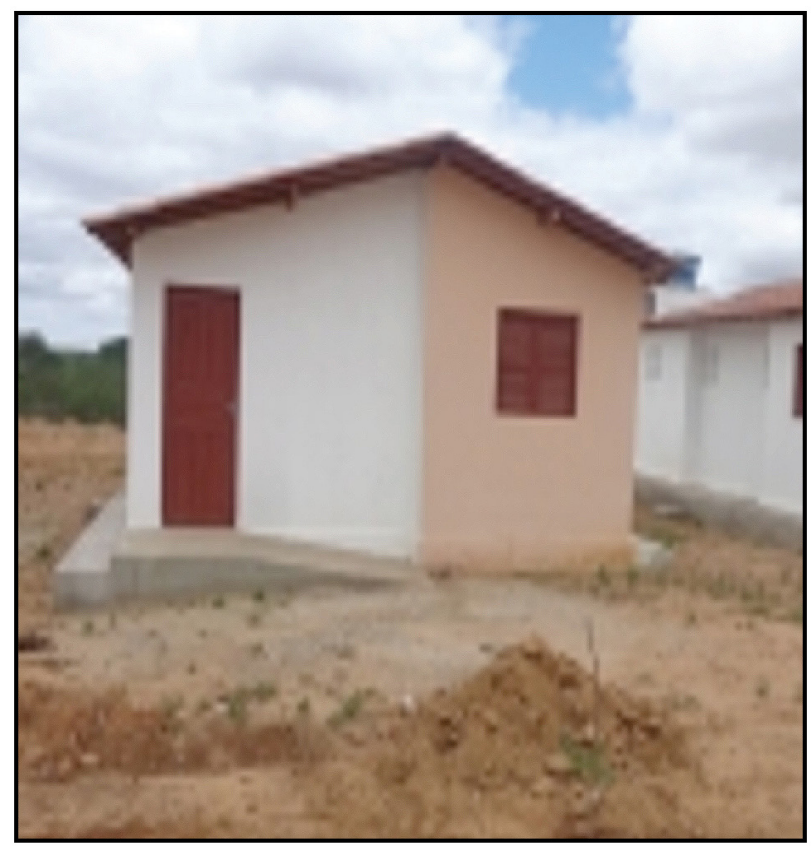

Figura 2 - Unidade Habitacional Santo André - PB (concluída) Fonte: ABC (2014). 


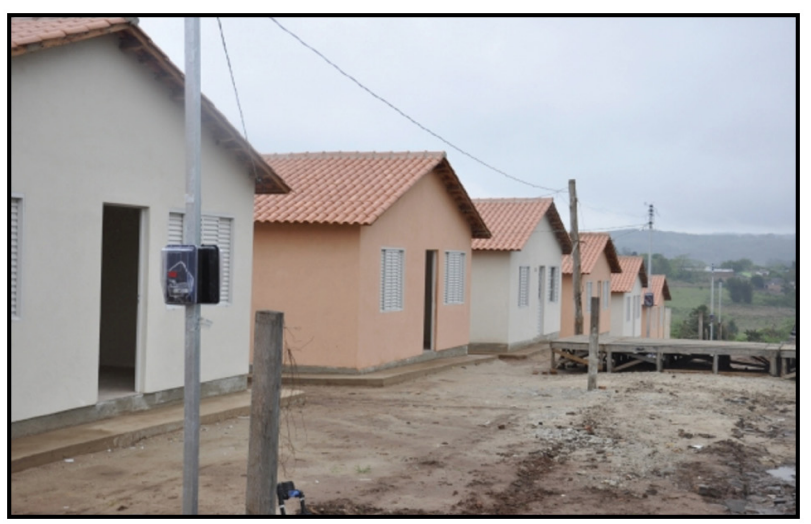

Figura 3 - Unidade Habitacional São Pedro do Sul - RS Fonte: ABC (2014).

observam-se fragilidades no cumprimento das especificações mínimas de infraestrutura urbana, por exemplo, arruamento, passeios públicos e condições para tráfego de veículos.

Outro ponto a ser observado refere-se às dificuldades para a construção dos empreendimentos na modalidade sub - 50 mil, por exemplo, em relação ao acesso à matéria-prima (cimento, areia, tijolos entre outros) e à quantidade necessária para a execução do empreendimento. Em geral, tais materiais não estão disponíveis no município de origem do empreendimento, o que implica a aquisição de matéria-prima em outros municípios nem sempre próximos, o que provoca custos à obra e reduz a atratividade às grandes e médias construtoras.

Acrescentem-se a essas dificuldades, o direcionamento do mercado e a fragilidade, ou mesmo a omissão, do poder público municipal de articular estratégias de planejamento contidas nos planos diretores ou nos planos locais de habitação, que deveriam orientar a formulação de políticas, as ações para o fomento à moradia social integrada ao tecido urbano, poderiam contribuir para reverter o atual cenário de produção de moradias no país, que produz cidades espraiadas e amplia o passivo urbano em médio e longo prazo.

No entanto, a reversão desse processo é um grande desafio, em especial para os municípios que possuem população inferior a 20 mil habitantes, haja vista que estes, em sua maioria, estão começando a instituir instrumentos básicos da política urbana, como a elaboração de planta cadastral, a implementação de leis de zoneamento, a delimitação do perímetro urbano, a legislação para especificar os tipos de uso e ocupação do solo, essenciais para o ordenamento do território.

A ausência de Lei de Perímetro Urbano dificulta conter o espraiamento da cidade, e consequentemente impõe a necessidade de extensão das redes de infraestrutura urbana e serviços públicos num contexto no qual são significativas as carências. Além disso, a ausência de estratégia de transição da área rural para a área urbana promoveria a valorização excessiva da terra e comprometeria a utilização para agricultura, pesca ou outros usos fontes de geração de renda para parcela da população (Akaishi, 2011, p. 46).

Considerando estes desafios, os pequenos municípios apresentam grandes dificuldades em operacionalizar os atuais programas habitacionais. Ao mesmo tempo, não existe um plano estratégico que vise ajustar os problemas identificados e propor um desenho de programas habitacionais mais adequado à realidade dos pequenos municípios.

As recentes ações do governo federal em relação à provisão habitacional destinada aos pequenos municípios revelam o descasamento entre a realidade destes municípios, que em pouco mais de dez anos estão estruturando mecanismos de gestão urbana com prementes dificuldades de elaboração e implementação dos seus planos locais de habitação. Também revelam as dificuldades de se enquadrarem no desenho de programas habitacionais padronizados e distantes da realidade e dos problemas habitacionais enfrentados pelos gestores locais.

\section{Considerações finais}

O programa Minha Casa, Minha Vida, em certa medida, viabilizou o acesso do poder público local e da população de baixa renda ao financiamento habitacional. No entanto, é preciso considerar que a formulação dos programas habitacionais não pode se resumir a proposições de ações e estratégias que padronizem as formas de atendimento das necessidades habitacionais, e que ao final se tenham unidades habitacionais desprovidas de qualidade urbanística e desintegradas do território. É necessário enfrentar as causas estruturais e repensar os próprios modelos da política habitacional e os vários níveis de gestão 
estratégica, para o enfrentamento de problemas comuns nos distintos municípios brasileiros com a participação da sociedade, agentes privados, poder público em seus vários níveis e agentes.

É notória a baixa efetividade do Programa Minha Casa, Minha Vida no atendimento às necessidades habitacionais de baixa renda e a sua pouca adesão no que diz respeito às premissas e objetivos da Política Nacional de Habitação e ao fortalecimento do SNHIS. Observam-se duas ações distintas do governo federal no enfrentamento da questão habitacional. Uma tem fortes subsídios atrelados à demanda na provisão da moradia social e frágeis mecanismos de articulação para a promoção do acesso à terra urbanizada e produção de moradias integradas ao território. Trata-se da situação dos atuais empreendimentos do programa Minha Casa, Minha Vida, destinado à população de baixa renda, o que tem gerado uma expansão periférica do tecido urbano em consonância com a omissão ou baixa capacidade dos agentes públicos nas estratégias de planejamento urbano. A outra trata-se da regulamentação do Sistema Nacional de Habitação de Interesse Social, com propostas para atender, de forma diversificada, às necessidades habitacionais atreladas a mecanismos para o controle do uso e ocupação do solo, porém com parcos recursos para a implementação dos objetivos propostos. Vale enfatizar que o SNHIS, na atual conjuntura, não se constitui em uma prioridade na agenda estratégica do governo.

É um desafio a produção de moradia social bem localizada, porém a forma tradicional e sucessiva dos governos na implementação de programas habitacionais destinados ao atendimento da população de baixa renda padroniza e periferiza as tipologias, e cada vez mais reafirma o modelo da cidade segregada, pela ausência de uma política urbana que enfrente a questão fundiária e potencialize a mistura de usos e faixas de rendas nos empreendimentos em sintonia com as distintas necessidades habitacionais de cada segmento populacional.

No caso dos pequenos municípios, objeto deste artigo, reconhece-se o aquecimento econômico proporcionado pela contratação e provisão de moradias. Trata-se de ações que induzem os gestores públicos a elaborarem planos e aperfeiçoarem suas legislações, a despeito de a deficiente capacidade institucional e técnica se constituir uma barreira a ser vencida. Ainda que o desenvolvimento de planos e legislações se coloque como uma importante ferramenta para a gestão urbana, tratados de forma setorializada, eles não asseguram a promoção de cidades mais justas. A questão é complexa e envolve mudanças estruturais nos rumos atuais que orientam as ações de desenvolvimento urbano gestadas de forma setorializada e simétrica, para o atendimento das necessidades locais e cada vez mais conduzidas pela lógica do setor privado.

Este artigo teve por objetivo analisar a adesão às diretrizes da política atual de habitação e sua efetivação por meio da modalidade Oferta Pública de Recursos, que integra o programa Minha Casa, Minha Vida. Essa modalidade é destinada aos municípios com população de até 50 mil habitantes, proporcionando a identificação e os avanços no planejamento urbanohabitacional e, também, revelando as dificuldades dos pequenos municípios quanto ao atendimento das necessidades habitacionais.

Espera-se, com a exposição ainda que preliminar da temática, que sejam possíveis novas contribuições e análises para o aperfeiçoamento e adesão às políticas conectadas à realidade dos pequenos municípios brasileiros.

\section{Referências}

Akaishi, A. G. (2011). Desafios do planejamento urbanohabitacional em pequenos municípios brasileiros. Revista de Pesquisa em Arquitetura e Urbanismo, 14(2), 41-50.

Akaishi, A. G. (2013). Planejamento e gestão habitacional em pequenos municípios brasileiros: o caso de Água Fria no semiárido baiano (Dissertação de mestrado). Programa de Pós-Graduação em Planejamento e Gestão do Território, Universidade Federal do ABC, São Paulo.

Associação Brasileira de COHABs e Agentes Públicos de Habitação - ABC. (2014). Banco de apresentações dos Fóruns Nacionais de Habitação. Brasília: ABC. Recuperado em 23 de abril de 2014, de http://www.abc.habitacao.org. br/index.php/eventos/forum/

Bonduki, N. (2013). Planos Locais de Habitação: das origens aos dilemas nas atuais nas regiões metropolitanas. In R. Denaldi. Planejamento Habitacional: notas sobre a precariedade e terra nos Planos Locais de Habitação (p. 45-48). São Paulo: Annablume.

Brasil. (2001, 10 de julho). Lei Federal no 10.257, de 10 de julho de 2001. Regulamenta os arts. 182 e 183 da Constituição Federal, estabelece diretrizes gerais da política urbana e dá outras providências. Brasília: Diário Oficial da União. 
Brasil. (2005, 16 de junho). Lei Federal no 11.124, de 16 de junho de 2005. Dispõe sobre o Sistema Nacional de Habitação de Interesse Social - SNHIS, cria o Fundo Nacional de Habitação de Interesse Social - FNHIS e institui o Conselho Gestor do FNHIS. Brasília: Diário Oficial da União.

Brasil. Ministério das Cidades. Secretaria Nacional de Habitação. (2008). Plano Nacional de Habitação: produto preliminar (No. 2). Brasília: Ministério das Cidades.

Brasil. (2009, 8 de julho). Lei Federal no 11.977, de 7 de julho de 2009. Dispõe sobre o Programa Minha Casa, Minha Vida-PMCMV e a regularização fundiária de assentamentos localizados em áreas urbanas; altera o Decreto-Lei no 3.365, de 21 de junho de 1941, as Leis nos 4.380, de 21 de agosto de 1964, 6.015, de 31 de dezembro de 1973, 8.036, de 11 de maio de 1990, e 10.257, de 10 de julho de 2001, e a Medida Provisória no 2.197-43, de 24 de agosto de 2001; e dá outras providências. Brasília: Diário Oficial da União.

Brasil. Ministério das Cidades. Secretaria Nacional de Habitação. (2010). Plano Nacional de Habitação: versão para debates. Brasília: Ministério das Cidades.

Brasil. (2011, 17 de junho). Decreto Federal no. 7.499, de 16 de junho de 2011. Regulamenta dispositivos da Lei no 11.977, de 7 de julho de 2009, que dispõe sobre o Programa Minha Casa, Minha Vida, e dá outras providências. Brasília: Diário Oficial da União.

Brasil. (2013, 13 de agosto). Portaria $n^{\circ} 363$, de 12 de agosto de 2013.Dispõe sobre as diretrizes gerais para aquisição e alienação de imóveis com recursos advindos da integralização de cotas do Fundo de Arrendamento Residencial - FAR, no âmbito do Programa Nacional de Habitação Urbana - PNHU, integrante do Programa Minha Casa, Minha Vida - PMCMV em municípios com população inferior a 50.000 (cinquenta mil) habitantes. Brasília: Diário Oficial da União.

Brasil. Ministério das Cidades. Secretaria Nacional de Habitação. (2014a). Ata da 43ª Reunião Ordinária do Conselho das Cidades realizada nos dias 1, 2 e 3 de dezembro de 2014. Brasília: Ministério das Cidades.

Brasil. Ministério das Cidades. Secretaria Nacional de Habitação. (2014b). Atendimento do Ministério das Cidades a Lei Acesso 12.527/2011, no âmbito do Poder Executivo Federal. Brasília: Ministério das Cidades.

Brasil. (2014c, 30 de janeiro). Portaria n- 45, de 29 de janeiro de 2014. Dispõe sobre as condições gerais para conclusão das obras remanescentes dos contratos firmados pelo Banco Morada S/A, por meio da Ação Provisão Habitacional de
Interesse Social, custeada pelo Fundo Nacional de Habitação de Interesse Social (FNHIS). Brasília: Diário Oficial da União.

Brasil. (2014d, 28 de abril). Portaria no 229, de 25 de abril de 2014. Define novo prazo para conclusão e entrega das unidades habitacionais contratadas por Instituições Financeiras (IF) e Agentes Financeiros (AF) habilitados no processo de Oferta Pública de Recursos regulamentado pela Portaria Conjunta SNH/STN n.o 472, de 18 de novembro de 2009, no âmbito do Programa Minha Casa, Minha Vida Oferta Pública para municípios com população até 50.000 habitantes. Brasília: Diário Oficial da União.

Confederação Nacional de Municípios - CNM. (2013a). $O$ atual cenário das políticas no setor habitacional: o Sistema Nacional de Habitação de Interesse Social: estudos técnicos. Brasília: CNM.

Confederação Nacional de Municípios - CNM. (2013b). Estudos técnicos. Brasília: CNM.

Fix, M. (2011). Financeirização e transformações recentes no circuito imobiliário no Brasil (Tese de doutorado). Universidade Estadual de Campinas, Campinas.

Instituto Brasileiro de Geografia e Estatística - IBGE. (2010). Censo Demográfico - 2010. Rio de Janeiro: IBGE.

Instituto Brasileiro de Geografia e Estatística - IBGE. (2011). Perfil dos municípios brasileiros. Rio de Janeiro: IBGE.

Instituto de Pesquisa Econômica Aplicada - IPEA. (2012). o programa Minha Casa Minha Vida em municípios de até 50 mil habitantes: quadro institucional e prognósticos da provisão habitacional de interesse social (Comunicado Ipea, No. 194). Brasília: IPEA.

Krause, C., Balbim, R., \& Lima, V. C., No. (2013). Minha Casa Minha Vida, nosso crescimento: onde fica a política habitacional? (Texto para discussão, No. 1853). Brasília: IPEA.

Olanda, E. R. (2008). As pequenas cidades e o vislumbrar do urbano pouco conhecido pela Geografia. Ateliê Geográfico, 2(2), 183-191.

Sposito, M. E. B. (2010). Novas redes urbanas: cidades médias e pequenas no processo de globalização. Revista Geografia, 35(1), 51-62.

Veiga, J. E. (2002). Cidades imaginárias: o Brasil é menos urbano do que se calcula. Rio de Janeiro: Autores Associados.

Recebido: Out. 01, 2014

Aprovado: Jan. 05, 2015 